\title{
Metrópole e forma urbana: entre a dialética negativa e a utopia
}

\author{
Metropolis and urban form: \\ between negative dialectics and utopia
}

Carolina Akemi Martins Morita [I]

\begin{abstract}
Resumo
Este artigo parte da discussão sobre a individualidade moderna sob perspectivas diversas, como as de Cacciari, Adorno e Horkheimer, para, assim, compreender a constituição da psicologia da sociedade de massas, pautada na produtividade e na utilidade, de maneira inter-relacionada e, até mesmo, imanente à própria metrópole. Busca-se, então, um contraponto, por meio da dialética, da forma urbana e da utopia propostas por Lefebvre, de modo a lançar luz sobre a seguinte questão: se a dialética negativa nos ampara ao questionar a identidade entre sujeito e objeto, teoria e prática, o confrontamento com a perspectiva dialética lefebvriana problematiza os limites do próprio pensamento e parece apontar para a utopia concreta como horizonte capaz de alimentar o espaço diferencial e o devir.
\end{abstract}

Palavras-chave: individualidade; metrópole; urbano; dialética; utopia.

\begin{abstract}
This article discusses modern individuality from different perspectives, such as those of Cacciari, Adorno, and Horkheimer, to understand the constitution of the psychology of mass society, based on productivity and utility, as interrelated with and even immanent in the metropolis itself. Therefore, we seek a counterpoint through the dialectics, urban form and utopia proposed by Lefebvre to shed light on the following question: if negative dialectics supports us when questioning the identity between subject and object, theory and practice, confrontation with the Lefebvrian dialectic perspective problematizes the limits of thought itself and seems to point to concrete utopia as a horizon capable of feeding the differential space and the becoming.
\end{abstract}

Keywords: individuality; metropolis; urban; dialectics; utopia. 


\section{Introdução}

Os homens sempre tiveram que escoIher entre submeter-se à natureza ou submeter a natureza ao eu. Com a difusão da economia mercantil burguesa, o horizonte sombrio do mito é aclarado pela razão calculadora, sob cujos raios gelados amadurece a sementeira da nova barbárie. Forçado pela dominação, o trabalho humano tendeu sempre a se afastar do mito, voltando a cair sob o seu influxo, levado pela mesma dominação. (Adorno e Horkheimer, 1985, p. 38)

A incursão do homem à modernidade é comumente caracterizada pela emergência e hegemonia do esclarecimento enquanto princípio ou categoria regente da vida em seus diversos âmbitos, seja por aqueles que encaram seus frutos de um ponto de vista mais pragmático, a saber, considerando as conquistas concretas em termos de desenvolvimento e inovação material obtidos especialmente a partir do século XVII, seja do ponto de vista da filosofia ou da teoria crítica, ao confrontar o esclarecimento propriamente dito com uma complexidade de questões que se mostram convergentes. Tanto em um como em outro caso, com perspectivas mais ou menos otimistas, vemos entrelaçadas, à consolidação do esclarecimento, temas como a inovação e o progresso, o domínio do homem sobre a natureza, a eficiência, a racionalidade e a produtividade, o trabalho como palavra de ordem, a ascensão da metrópole e do urbano - em substituição à dualidade entre cidade e natureza. Mas também o declínio do indivíduo - como anunciado por Adorno e Horkheimer - em função do surgimento das massas, a psicologia destas emergindo como matriz fundamental para processos obscurantistas como o fascismo, a dialética entre a dominação e a libertação; enfim, uma eterna aporia que insiste em enquadrar a promessa de emancipação ao inevitável sacrifício ou, em outros termos, o esclarecimento ao próprio mito.

Diante desse cenário, cujas raízes remontam especialmente à transição entre os séculos XVIII e XIX, mas cuja estrutura mostra-se ainda bastante atual e latente, este artigo apresenta-se como uma tentativa de relacionar a forma da metrópole - enquanto forma geral assumida pela racionalização das relações sociais como desdobramento da racionalização das relações de produção (Cacciari, 1993), a saber, o local da produção e da reprodução, da funcionalidade e da utilidade - com manifestações sociais modernas, tais como a psicologia das massas e até mesmo o fascismo. Para tanto, discutiremos a individualidade moderna a partir do diálogo entre análises diversas, como as de Massimo Cacciari, Georg Simmel, Walter Benjamin, Theodor Adorno e Max Horkheimer, Georges Bataille, para, assim, compreender a constituição da psicologia da sociedade de massas de maneira inter-relacionada e, até mesmo, imanente à própria metrópole. Também, mostra-se igualmente como um objetivo deste artigo realizar um paralelo entre a metrópole e o urbano, tal como vislumbrado pelo filósofo Henri Lefebvre, com vistas a compreender de que maneira a forma urbana pode ou não implicar, imperativamente, a configuração (pós) metropolitana que temos testemunhado atualmente. Isto é, seriam a metrópole - em Cacciari, como uma verdadeira degeneração do sentido tradicional de cidade - e o urbano - em Lefebvre, como um horizonte do possível-impossível - coincidentes? 0 que tencionamos sustentar sugere 
que o urbano faça referência a um aspecto formal em Lefebvre, enquanto a cidade e a metrópole seriam seus possíveis conteúdos, com orientações ideológicas mais ou menos definidas historicamente.

\section{A noção de Individualidade}

Iniciaremos nosso percurso com Adorno e Horkheimer em sua aporia no processo de constituição do esclarecimento e da formação da subjetividade moderna. Primeiramente, a individualidade aparece em Horkheimer (2002) como um conceito histórico específico que indica certa tomada de consciência do homem perante suas condições de existência, de forma a assumir uma postura ativa e apta à subsunção de seus condicionantes, em detrimento de uma posição passiva, resignada e subordinada.

Ora, o modelo de indivíduo aqui é o herói grego, sobretudo o Ulisses idealizado por Homero, que se caracteriza por sua astúcia e se autossacrifica para poder, assim, sobreviver e preservar-se. Temos, portanto, no cerne desse esclarecimento, uma relação controversa e dialética entre dominação e exploração, conservação e sacrifício, individualização e imitação, racionalidade, ou esclarecimento, e mito. Tais paradoxos apontados por Adorno e Horkheimer na Dialética do esclarecimento (1985) derivam do próprio princípio da ação em Ulisses, que se vale da astúcia e de estratagemas para vencer uma natureza que se mostra implacável. Esse "método" ulissiano contradiz a essência do método racional cartesiano por excelência, matriz do pensamento ocidental, cuja dúvida buscaria desofuscar, justamente, as ilusões e os imbróglios causados por certo "gênio maligno, não menos astucioso e enganador que poderoso, que dedicou todo o seu empenho em enganar-me" (Descartes, 1999, p. 255). A astúcia e o sacrifício presentes no mito implicam uma espécie de mentira e uma violência, por meio de uma sequência de substituições e compensações que se utilizam da própria irracionalidade como alguns dos principais figurantes da racionalidade. Pois Ulisses sobrevive às forças da natureza e ao canto das sereias, anulando-se, em uma espécie de morte do eu por meio de um procedimento mimético, para assim poder sobreviver; "o astucioso só sobrevive ao preço de seu próprio sonho, a quem ele faz as contas desencantando-se a si mesmo bem como aos poderes exteriores" (Adorno e Horkheimer, 1985, p. 55). A fórmula do esclarecimento dita que o homem deve tornar-se ninguém para, em promessa, sobreviver enquanto indivíduo.

Apenas a título de esclarecimento e reflexão a esse respeito, vale abrir um parêntese para destacar que um dos estudiosos recentes a respeito do mito, Elíade (1972, p. 6), o conceitua não apenas como um significado paralelo e independente da realidade, uma ilusão que não tem existência real, mas, sim, como algo:

\footnotetext{
"Vivo" no sentido de que fornece os modelos para a conduta humana, conferindo, por isso mesmo, significação e valor à existência. Compreender a estrutura e a função dos mitos nas sociedades tradicionais não significa apenas elucidar uma etapa na história do pensamento humano, mas também compreender melhor uma categoria dos nossos contemporâneos.
} 
Isso significa atribuir uma concretude ao mito, a despeito de sua presumível intangibilidade ou caráter etéreo, e que vai muito além de crenças e rituais considerados primitivos, mas que, talvez pudéssemos dizer, efetivamente faz parte de certo mecanismo de funcionamento do pensamento humano. Portanto, parece ser irrefutável assumir que o mito envolve projeções - geralmente articulando passado e futuro - que estabelecem vínculos e direcionam os atos presentes. Como complementa o filósofo Lefebvre (2008), o mito implica uma reflexão sobre a natureza de algo: indica um nascimento, explica o presente e evoca um futuro. Trata-se de uma narrativa tradicional que pretende explicar a origem e a existência das coisas, lançando mão de um pensamento fantasioso, e não necessariamente de uma racionalidade.

Ao analisar um mito, devemos atentar para seus anacronismos. Tudo tem sentido e objetivo no mito, visto que tudo deve fazer sentido na e para a sociedade em que foi criado; não obstante, seus componentes propriamente ditos frequentemente não pertencem a tal período em que ele foi, de fato, concebido. Por exemplo, mitos do período industrial podem utilizar-se de elementos pertencentes ao período agrário precedente; mitos do período agrário, por sua vez, lançam mão de noções derivadas de um momento nômade e pastoril. Isso porque esses elementos que compõem o mito são retirados de certo contexto - não raro precedente - e rearranjados, remanejados, num período posterior. Tal mecanismo não deixaria de operar como algo bastante funcional e útil: deslocando-se o mito de seu contexto original, tendemos a buscar suas justificativas e referenciais naquele próprio contexto de onde (supostamente) tem origem, mas não no contexto presente e atuante - onde ele talvez não se explicasse, mas onde efetivamente deve operar. 0 mito passa a se comportar como uma forma a se autorreferenciar, de sorte que a (i)lógica presente no discurso mitológico se ofereça como imanente a ele mesmo, ao mesmo tempo que deve inspirar certa lógica e racionalidade comportamental no contexto deslocado em que se faz aplicar. Para Lefebvre, em termos de representações da realidade, o mito coaduna-se, não necessariamente de maneira harmoniosa, com outros dois conceitos - a utopia e a ideologia - como vemos abaixo:

O mito definir-se-ia como discurso não institucional (não submetido às imposições das leis e instituições), extraindo seus elementos no contexto. A ideologia consistiria num discurso institucional, justificando, legitimando (ou então criticando, recusando e refutando) as instituições existentes, mas desenvolvendo-se no seu plano. Quanto à utopia, ela se empenharia em transcender o institucional, servindo-se ao mesmo tempo do mito, da problemática do real e do possível-impossível [...]. Diante dessa tríplice aliança - o mito, a ideologia, a utopia -, os conflitos resolvem-se por magia: atribuídos ao passado ou reportados ao futuro. Onde, então, se apresentam? Na obra de arte. (Ibid., p. 98)

Lefebvre sugere certa ascendência dessas "unidades significantes" (ibid., p. 100), dessas "re-presentações" que se imiscuem e oscilam entre si, em termos das facetas da realidade e, consequentemente, no processo de emergência da Cidade ou da Cité. Pois a cité, em sua origem, retoma os temas da tragédia grega elucidados por Nietzsche, isto é, enquanto oposição entre Apolo - a razão proporcionada pela cidade - e Dionísio - o universo temeroso do campo. E, então, deparamo-nos com 
outra questão que se mostra inerente à formação da individualidade: sua interdependência em relação ao contexto em que está inserida, ao substrato, a uma dimensão espaço-temporal peculiar. Obviamente, mesmo nesses termos, a formação da individualidade não poderia deixar de apresentar uma série de nuanças. Retomemos um pouco dessa historicidade.

No que diz respeito à origem das cidades, inicialmente, as trocas e o comércio estabeleciam uma relação heterotópica com as cidades (limitados a lugares especializados), dado que aqueles que deles se ocupavam teriam uma participação funcional (geradora de riquezas e movimento), porém não políti$c a$ da cidade. Apesar dessa não coincidência entre cidade funcional e política, "a cidade política acompanha, ou segue de perto, o estabelecimento de uma vida social organizada, da agricultura e da aldeia" (ibid., p. 19). Nesse sentido, a emergência do indivíduo remontaria inevitavelmente à própria polis grega, local de equilíbrio entre o Estado e os cidadãos, em que coexistem a capacidade de domínio sobre outrem - o coletivo, os interesses da comunidade - e a liberdade individual, tais como prefigurados na "República" de Platão. Visto que "o habitante da cidade é o indivíduo par excellence" (Horkheimer, 2002, p. 136), a individualidade logo surge a partir de uma contraposição, um antagonismo entre o sujeito e as condições de sua existência, sejam elas de caráter social, econômico, espacial.

Em que pese essa mutualidade essencial entre indivíduo e cidade, Horkheimer mostra-nos que, nessa ontologia de Platão, poderíamos identificar certa indiferença e passividade, por conta de sua distinção entre uma razão objetiva e a razão subjetiva e formalizada. Isto porque não seria nenhuma novidade dizer que certas condições sociais já estariam dadas e inquestionadas na estrutura platônica, isto é, os únicos aptos a participar e viver nesse equilíbrio harmonioso - entre homem e cidade ou entre homem e coletividade - seriam aqueles que atendessem aos requisitos para o status de cidadão. Escravos, mulheres, crianças, estrangeiros estariam, portanto, excluídos desse "esquema", de modo que sua virtude consistiria em seu oposto: a obediência e não a contraposição.

Por esse motivo, Horkheimer assevera que, mesmo em Platão, reinaria ainda uma visão estática da história, em que a personalidade se colocaria como microcosmo harmonioso das relações e hierarquias existentes (natural e social), sem postular um horizonte de "emancipação progressiva do sujeito de uma eterna infância tanto na comunidade quanto na natureza" (ibid., p. 138). Consequentemente, a perspectiva republicana de Platão poderia ser considerada fria e de certa forma indiferente, distinta da visão assumida por Sócrates, para o qual o principal parâmetro para a constituição da individualidade estaria fundado na reflexão, na medida em que esta pressupõe uma contraposição entre o sujeito e sua realidade externa. A essência da individualidade socrática apresentada por Horkheimer consistiria não no equilíbrio ou harmonia entre o indivíduo e sua esfera de existência; pelo contrário, a base para essa individualidade estaria dada na medida em que houvesse contraste, oposição e tensão entre sujeito e sua realidade.

Nesse momento, tornam-se evidentes as distintas expressões da cidade, como pontuado por Cacciari (2010), uma vez que, em termos ontológicos e genealógicos, a polis grega e a civitas romana apresentariam várias divergências entre si: 
Na civilização grega, a cidade é fundamentalmente a unidade de pessoas do mesmo gênero e, portanto, pode-se entender como polis uma ideia que se remete a um todo orgânico, precedente à ideia de cidadão. Por outro lado, desde suas origens - como o próprio mito romano fundador narra -, em Roma, a cidade é a concorrência conjunta, a convergência de pessoas muito diferentes por religião, etnia etc., que concordam apenas em virtude da lei. (Ibid., p. 11; tradução nossa) $)^{1}$

Em todo caso, essa cidade política quer se considere a polis, dos semelhantes que compartilham de um mesmo ethos, ou a civitas, dos diferentes que se submetem a uma mesma lei/regime (concordia) -, ao assumir primazia em relação ao campo, não poderia ser compreendida sem se ancorar no papel desempenhado pela escrita, que se relaciona diretamente às convenções e, sobretudo, ao poder. Pois: "ela é inteiramente ordem e ordenação, poder [...]. A cidade política administra, protege, explora um território frequentemente vasto [...]. Aí, a propriedade do solo torna-se propriedade eminente do monarca, símbolo da ordem e da ação" (Lefebvre, 2008, p. 19).

Essa expressão política da cidade enquanto domínio sobre o território ganharia sensível impulsão com a urbis romana e sua propensão à "globalização", através da expansão territorial do império. A Roma mobilis, destaca Cacciari (2010), seria essencial ao atribuir uma mobilidade e dinamismo à cidade e, sobretudo, ao conferir a ela um fim, uma direção - o imperium sine fine. Com efeito, se, anteriormente, a polis grega representava 0 exemplo da cidade política, a cité romana, e mais especificamente a urbis, torna-se o local em que a racionalidade passaria a mostrar sua prevalência. Seu aspecto aberto e dominador contrapõe-se à dimensão fechada e contida da cidade grega, como também nos mostravam autores como Benévolo (2015), para quem a nova escala adquirida pela cidade romana transparecia nos desenhos das ruas e estradas que não apenas ganhavam uma nova proporção, mas um desenho sistemático, visto que o investimento em construções infraestruturais coincidiria com o movimento de dominação territorial. Sinais dessa mentalidade colonizadora romana poderiam ser percebidos pelo seu próprio traçado retilíneo e quadriculado - seguindo a mesma lógica do loteamento do campo, mas também remontando aos eixos cardo e decumanos - centuriatio romana - que conferiam a medida e a régua para o tabuleiro de origem militar.

Estágio que marca os primórdios da manifestação do urbano, propugnado como uma hipótese teórica por Lefebvre, ou da metrópole, tal como analisada por Cacciari, como veremos à frente, em que o domínio e hegemonia da lógica da cidade - do Logos, tal como prenunciado pelo urbi et orbi romano - sobre as mais diversas esferas da vida e, consequentemente, sobre o campo, marcam o nascimento do que Lefebvre denominará segunda natureza do homem. Nesse contexto, 0 aspecto homogeneizante passaria a prevalecer sobre o caráter de tensão próprio do conceito de individualidade.

Ora, o que pretendemos ressaltar com esse percurso consiste na dialética entre individualização - enquanto processo instituinte, de contraposição e tensão - e individualidade - 0 instituído. 0 problema residiria, portanto, no que a filosofia passasse a negar essa sua essência de tensão e a buscar, paulatinamente: um equilíbrio de maneira idealizada e idílica, que vem a funcionar como uma espécie de 
consolo. Ou, igualmente, o seu extremo oposto: na medida em que o homem passasse a se esquivar do sofrimento e do conflito e se resignasse em sua independência ilusória, enquanto ser autossuficiente e isolado dos problemas que 0 envolvessem. Em ambos os casos, assevera Horkheimer, perde-se a individualidade, como também a própria política, uma vez que:

Existe uma moral em tudo isso: a individualidade é prejudicada quando cada homem decide cuidar de si mesmo. À medida que o homem comum se retira da participação nos assuntos políticos, a sociedade tende a regredir à lei da selva, que esmaga todos os vestígios da individualidade. 0 indivíduo absolutamente isolado sempre foi uma ilusão. As qualidades pessoais mais estimadas, tais como a independência, o desejo de liberdade, a simpatia e o senso de justiça, são virtudes tão sociais quanto individuais. $\mathrm{O}$ indivíduo totalmente desenvolvido é a consumação de uma sociedade totalmente desenvolvida. A emancipação do indivíduo não é uma emancipação da sociedade, mas resultado da liberação da sociedade da atomização. Uma atomização que pode atingir o cume nos períodos de coletivização e cultura de massas. (Horkheimer, 2002, p. 140)

E é nesse ponto, com o homem moderno, que nos deparamos com a atual crise do indivíduo, visto que hoje "esse antagonismo é suplantado na mente consciente dos indivíduos pelo desejo de se adaptarem à realidade" (ibid., p. 136), que se relaciona dialeticamente com a crise do conceito tradicional de cidade. Para Horkheimer, em termos históricos, o valor da individualidade drenado como resignação diante dos problemas terrenos emerge de maneira reforçada e consolidada com o Cristianismo, que coloca a vida na Terra como mera passagem, deslocando a ideia de autopreservação para um status de mediação metafísica, em que o autossacrifício se apresenta como moeda de troca para a redenção da alma na eternidade, dadas a efemeridade e a futilidade da vida terrena. Nesse contexto, a individualidade é substituída pelo individualismo - reforçado pelas leis do mercado livre - remontando a um conformismo generalizado; a sociedade das massas torna-se, assim, o abrigo das mônadas, "símbolo setecentista do indivíduo econômico atomístico da sociedade burguesa", as quais, por mais "isoladas que estivessem pelo abismo do autointeresse, tenderam, contudo, a se tornarem cada vez mais semelhantes pela busca desse interesse" (ibid., p. 144).

Como resultado, atualmente, não se postula um futuro que se possa determinar, visto que cada indivíduo se preocupa com a satisfação de um presente cada vez mais efêmero. 0 indivíduo, enquanto mônada, reduz-se a uma "célula de reação funcional" (ibid., p. 149). Ora, nesse percurso surpreendente realizado por Horkheimer, a individualidade estaria comprometida no âmbito tanto das massas, mas também no das tão aclamadas elites: na primeira, dado que a possibilidade de satisfação e de se atingir a manutenção dessa vida "segura e material" se encontra um tanto longínqua, de modo a não justificar os sacrifícios; na última, pela primazia exacerbada dada aos objetos materiais, ao lucro e ao poder, o que acaba transformando o indivíduo num servo destes, em detrimento da individualidade genuína, que buscaria sobrepujá-los.

Em termos de sobrevivência, o homem passa a perceber que sua autopreservação depende de sua capacidade de imitar, de mimetizar, de assimilar, de repetir. Muito embora diversos autores atestem que a mimese tenha 
sempre feito parte da formação do indivíduo, ${ }^{2}$ ela se torna lei que predomina de maneira esmagadora hoje. A necessidade de se adequar a certos grupos existentes, o imperativo de seguir regras e moldes de comportamento que legitimem a ascensão social, a ânsia por se sentir incluso e parte do todo, enfim, uma somatória em que as partes devem ser mutiladas e o todo se constitui por exclusão. Pois o que dita a sobrevivência, na contemporaneidade, depende do quanto se consegue fazer identificar com os modelos existentes, e não sua capacidade de se contrapor e fazer frente a eles. Mesmo na Idade Média, argumenta Horkheimer, em que a realidade era dada como uma verdade objetivada - e totalizante calcada num conformismo e com poucas brechas para questionamentos, haveria certos antagonismos entre teoria e prática, vida espiritual e vida material. Pois, ainda que se colocassem de maneira objetivada, as realidades anteriores à hodierna ainda apresentariam mais lacunas do que a "superorganização moderna", cujo corolário é expresso pela indústria cultural de massas, em que a ênfase no indivíduo emerge como parte funcional e operante da lógica do sistema socioeconômico capitalista. Hoje, não há mais contraposição à realidade, e a indústria de massas vem a corroborar essa inversão de papeis - visto que, outrora, a arte supunha um distanciamento mínimo, senão crítico, em relação à vida -, mostrando-se fiel àquela, na medida em que a exalta tal como é.

Tal conjuntura, para Adorno e Horkheimer, não deixaria de ser totalizante e totalitária, uma vez que "atinge igualmente o todo e a parte", de modo que "o todo e o detalhe exibem os mesmos traços, na medida em que entre eles não existe nem oposição nem ligação" (1985, p. 104). A violência velada da indústria cultural impõe o seu crivo - de maneira não menos inflexível e inexorável que processos mais explicitamente totalitários, como o próprio fascismo - que decanta, categoriza e pasteuriza quaisquer singularidades segundo suas leis.

Como verdadeiro desfecho desse novo esquema da individualidade moderna, apresenta-se um aspecto que faltava às sociedades antigas: a perspectiva de transformação que se delineia como um horizonte tangível. Uma possibilidade que, no entanto, não consiste na utopia em seu sentido - ainda que nem tão estrito - outrora conferido por Thomas More, nem mesmo numa utopia que nos parece um pouco mais tangível do "possível-impossível" buscada por teóricos como Henri Lefebvre, nem tampouco como uma heterotopia foucaultiana, ou seja, como realidades alternativas, ou até mesmo contrapostas, à vigente. Pelo contrário, o logro que se almeja se assemelha, tal como já apontara Benjamin, com a vitória num jogo, em que as regras estão dadas e tudo se passa como se dependente, exclusivamente, de atributos e capacidades pessoais.

Se o imanente substituiu generalizadamente o transcendente, se qualquer elemento de tensão ou contradição - possibilitado pelo outro, enquanto desconhecido e em certa medida indomável - esvai-se, é precisamente nesse sentido que poderíamos dizer que também a individualidade perde o seu lugar na atualidade, concretizando o "declínio do indivíduo" de Horkheimer (2002) ou a "degeneração do sujeito", mais recente, de Laclau (2013). De fato, enquanto processo dialético, a individualidade não pode pressupor a sua plena instituição - a racionalização da realidade por completo -, visto que isso demarca a sua própria derrocada. Além disso, mesmo enquanto processo instituinte, o esclarecimento 
e a individuação não deixam de enfrentar outras contradições que lhes são inerentes, pelo embate constante quanto à relação de continuidade ou descontinuidade que estabelecem com o status quo, como vimos acima. Como já nos advertiam Adorno e Horkheimer (1985), no âmago do esclarecimento, podemos enxergar certos elementos que denunciariam um ainda comprometimento com a lógica então vigente, seja pela instrumentalização de sua Razão ou, na melhor das hipóteses, por sua inocuidade no sentido de proporcionar mudanças efetivas, transformações na base do sistema e a longo prazo.

$O$ entendimento tem a intenção de livrar os homens do medo e torná-los senhores, vencer a superstição, para, assim, dominar a natureza desencantada. Sem embargo, os mitos aos quais, supostamente, o esclarecimento faz frente já seriam produtos desse mesmo esclarecimento nos tempos de outrora. Isto porque o mito teria tanto a intenção de descrever certa origem como de explicar, de justificar, de apresentar os motivos. Ora, atualmente, ele tornou-se regra: "o mito converte-se em esclarecimento, e a natureza em mera objetividade [...]. O princípio da imanência, a explicação de todo acontecimento como repetição, que o esclarecimento defende contra a imaginação mítica, é o princípio do próprio mito" (ibid., pp. 21-23).

Se a visão platônica estática da realidade poderia ser considerada um tanto fria, essa atual dinâmica do progresso não deixa de ser problemática:

Se as ontologias essencializam indiretamente as forças da natureza por meio de conceitos objetivados, e assim favorecem a dominação da natureza pelo homem, a doutrina do progresso essencializa diretamente o ideal de dominação da natureza e finalmente deriva, ela própria, numa mitologia estática e derivada. $\mathrm{O}$ movimento como tal, abstraído de seu contexto social e de sua finalidade humana, torna-se simplesmente uma ilusão de movimento, a infinidade inútil de uma repetição mecânica.

[...] A circunstância de que o cego desenvolvimento da tecnologia reforça a opressão e exploração social ameaça a cada passo transformar o progresso em seu oposto, o barbarismo completo.

Tanto a ontologia estática quanto a doutrina do progresso - ou seja, as formas objetivistas e subjetivistas de filosofia - esquecem o homem. (Horkheimer, 2002, pp. 138-139)

\section{Metrópole: local das relações formalizadas e das massas}

O homem pautado puramente pelo entendimento é indiferente frente a tudo que é propriamente individual, pois do individual originam-se relações e reações que não se deixam esgotar com o entendimento lógico - precisamente como no princípio monetário a individualidade dos fenômenos não tem lugar.

Pois o dinheiro indaga apenas por aquilo que é comum a todos, o valor de troca, que nivela toda a qualidade e peculiaridade à questão do mero "quanto". Todas as relações de ânimo entre as pessoas fundamentam-se nas suas individualidades, enquanto as relações de entendimento contam os homens como números, como elementos em si indiferentes, que só possuem um interesse de acordo com suas capacidades consideráveis objetivamente. (Simmel, 2005, pp. 579-580) 
Dado que a ideia do nascimento do indivíduo não possa ser considerada sem o conceito de cidade - enquanto uma organização espacial, sociopolítica e econômica específica -, o princípio do indivíduo moderno por excelência não poderia ser compreendido fora da metrópole. Simmel (ibid.), um dos pioneiros nessa discussão, define a metrópole como a forma socioespacial da realização da racionalidade do processo de produção capitalista, em que as relações aparecem formalizadas; trata-se do local da produção, da reprodução, da circulação e do valor de troca. Emergindo como uma dialética entre a vida nervosa - base psicológica, o valor de uso, a inovação contínua, os comportamentos e os adestramentos - e o intelecto - o homogêneo, a abstração, o quantitativo, o valor de troca -, a metrópole apresenta-se, então, como o local da produtividade e da utilidade, isto é, da preponderância da lógica do capital. Essa dinâmica imanente entre a vida nervosa e o intelecto possibilita a formação do Espírito (Geist), de sorte que é o Geist que necessariamente habita a metrópole.

É nesse contexto que emergem dois conceitos paralelos - se não coincidentes examinados, respectivamente, por Simmel e por Benjamin, a partir da análise do poeta Baudelaire: a atitude blasé e o choque, como os novos formatos de autoconservação do indivíduo na metrópole:

Nesse fenômeno peculiar de adaptação que é o caráter blasé, em que os nervos descobrem a sua derradeira possibilidade de se acomodar aos conteúdos e à forma da vida na cidade grande renunciando a reagir a ela - a autoconservação de certas naturezas, sob o preço de desvalorizar todo o mundo objetivo, o que, no final das contas, degrada irremediavelmente a própria personalidade em um sentimento de igual depreciação. (Ibid., 2005, pp. 581-582)

Blasé consiste, portanto, na indiferença em relação à multiplicidade qualitativa própria à experiência; não se trata da ausência da percepção, mas de sua internalização de maneira racional e intelectualizada, mediada pela razão. Como consequência, tem-se a perda do prazer, visto que a relação direta entre homem e objeto, por meio da experiência, aparece substituída por uma relação intelectualizada, tal como um comportamento ou adestramento. A espiritualização - Vergeistgung ou processo de formação do Espírito, do Geist - e a mercantilização fundem-se nessa atitude blasé, com a perda da afetividade de maneira generalizada; a partir de então, são dadas as bases para a vida do consumo, em que as commodities se relacionam através de equivalências, em que cada elemento - homens e objetos - mostra seu valor funcional, como se decorrente de um cálculo, dentro da metrópole. É como se o blasé reduzisse até mesmo as experiências cotidianas a coisas e à medida do intelecto (Verstand), de modo a completar o ciclo da perda da autonomia em função do espírito.

O filósofo Cacciari (1993) assevera, a partir de Simmel e Benjamin, que não se deve compreender o choque, entretanto, como uma reação à experiência vivida, como sua contraposição, como se ambos - a realidade externa e o choque - fossem efetivamente separados segundo uma visão dualista, ou mesmo como a síntese de uma relação dialética entre o sujeito e determinada realidade objetivada. Pelo contrário, o pensamento (dialético) negativo apresentado por Cacciari sugere uma 
contraposição calculada, de sorte que, na metrópole, não se poderia falar numa experiência vivida destituída, ou livre, do choque. $\mathrm{Na}$ metrópole, o próprio choque transforma-se no Erleibis - a experiência vivida.

O blasé e o choque indicam, antes, uma internalização da lógica vigente e certa tomada de consciência da impotência em superá-la, o que tende a legitimar a vida nervosa e o intelecto. Temos, assim, uma espécie de ideologia da metrópole que apresenta seu ciclo completo, visto que até mesmo a contradição assume uma função. Não se trata da crise enquanto oposição dentro do processo de crescimento capitalista na metrópole, mas da própria crise servindo para o funcionamento e a alimentação desse mesmo mecanismo.

Como compensação dessa alienação, faz-se necessária a ilusão da liberdade individual, incorporada, em essência, pela busca por igualdade e direitos, nos termos da divisão do trabalho. Apesar de essa busca por liberdade e autonomia, no interior da individualidade, transparecer em Simmel como uma espécie de síntese - ou uma sublimação reconciliadora tal perspectiva um tanto otimista não se faz presente no Baudelaire exposto por Benjamin, para quem o choque estaria desmistificado e dessacralizado como a única experiência viável na metrópole, relacionado a uma existência catastrófica e ao sentimento de melancolia e angústia, de modo a conformar uma espécie de "trágica" consciência da existência humana, no sentido nietzschiano do termo. Nessa existência, o caminhante internaliza e assemelha seu próprio movimento ao da circulação de uma commodity, incorporando o processo de socialização das relações de produção. Um tipo de existência que emerge com a constituição das massas, de maneira inextricável.
Para Cacciari, a atitude blasé indica, em última análise, a autonomia do signo, em que a razão especulativa kantiana não mais admite os limites de sua alçada, ao preconizar uma distinção entre o fenômeno e a coisa em si, ou entre o conteúdo e a forma. Para Benjamin, tudo tende a aparecer, agora, de maneira plenamente transparente, como passível de explicação e solução. Novamente, tal como num verdadeiro jogo, as regras estão definidas e pressupõe-se a sua decifração, contanto que não seja fora de sua própria lógica, mas como mera repetição ou reprodução. Os dados são as aparências, e o que importa é a articulação e concatenação de suas relações e nexos.

Nessa lógica da repetição, a reprodução volta a se consumar através do mito ("o mito da tecnologia", "o mito do progresso"), justificativas para sua dinâmica e movimento incessante, bem como de uma ideologia, de uma prática inconsciente e da perda da identidade individual e, sobretudo, coletiva. Em certo sentido, tal análise não se distancia da já realizada por Marx, ao definir o fetichismo da mercadoria, o qual implicaria uma autonomia dos objetos (signos) em relação a seus significados (valor de uso, produção enquanto processo), corroborada, mais recentemente, pelo "sistema dos objetos" proposto por Baudrillard (1969). ${ }^{3}$

De fato, o que temos visto, especialmente a partir da década de 1980, é justamente a generalização do universo da mercadoria aos mais diversos âmbitos da existência humana, a começar pelo próprio espaço social e penetrando paulatinamente nos mais distintos momentos da vida, com especial interesse para as dimensões cultural e espacial. O resultado, para o filósofo Lefebvre, seria a "cotidianidade", ou vida cotidiana regulamentada, regida e controlada em todos os seus âmbitos, em que até 
mesmo os resquícios - espaços de liberdade e lazer - são funcionais em termos de produção. Ao mesmo tempo, a "sobrevivência" emerge enquanto palavra de ordem, em substituição do que poderia ser um "desejo de viver" propriamente dito, marcando a emergência da "sociedade burocrática do consumo dirigido cunhada por Lefebvre" (1991a) para referir-se à cotidianidade, esse espaço-tempo não abandonado ou deixado à liberdade, mas produtivo. As passagens abaixo nos parecem decisivas:

A cotidianidade se tornaria assim, a curto prazo, o sistema único, o sistema perfeito, dissimulado sob os outros que o pensamento sistemático e a ação estruturante visam. Nesse sentido, a cotidianidade seria o principal produto da sociedade dita organizada, ou de consumo dirigido, assim como a sua moldura, a Modernidade. (Ibid., p. 82)

As formas perdem seus conteúdos, a começar pela mercadoria (forma imagem, sem seu conteúdo prático ou valor de uso), pelo trabalho (desconectado da totalidade do processo produtivo, bem como de seu produto), mas também passando pelo Estado (forma), que teria paulatinamente ganhado autonomia e não mais representaria, de fato, seu conteúdo - a sociedade civil. É precisamente nesse contexto que o Estado assume um papel crucial: dar coesão e coerência aos fragmentos e às mônadas, na medida em que estas viabilizam a manutenção de seu próprio funcionamento e de suas engrenagens.

A reprodução implica a cotidianidade, a qual, por sua vez, consuma-se através de certo terrorismo - a necessidade da segurança - e da programação da vida em função da mercadoria e do consumo. De sorte que não se trataria apenas de inculpar apenas uma ideologia, mas uma sequência de substituições ou um sistema de álibis, a serviço do pleno funcionamento do capital, e que se desdobra em ideologias apresentadas sob títulos de funcionalismo, racionalismo, estruturalismo, cientificismo. Por fim, teríamos a substituição do valor de uso pelo valor de troca de maneira generalizada.

A cidade-metrópole instaurada como a morada do logos (Lefebvre, 2016) expressa o seu poder totalitário das mais variadas formas: do virtuoso traçado Haussmanniano, instrumento da opressão e de uma estratégia de classe, à concepção do habitat como função abstrata e alienada da cidade propriamente dita - em substituição ao habitar -; decorrente, sobretudo, da crise habitacional do pós-guerra, vemos operando as mãos da racionalidade. ${ }^{4}$

\section{Individualidade moderna nas massas: entre a utilidade e o dever}


Nesse contexto da metrópole, em que a Subjetividade (o Geist) substitui o sujeito (o indivíduo), as massas, ou a multidão, aparecem como uma unificação de indivíduos que incorporam a busca por liberdade e autonomia, que sugere uma espécie de sublimação em Simmel, que indica, para Benjamin, uma existência catastrófica. A vida nervosa, como aceleração dos ritmos e mobilização constante, consolida-se por meio da noção de utilidade, erigida como atributo indispensável a determinar a inserção social do indivíduo moderno. Em El Estado y el problema del fascismo de Georges Bataille (1993), as noções de funcionalidade e homogeneidade da metrópole aparecem como competentes a certa psicologia pautada pela produção, e essa medida comum, como vimos acima, consiste no próprio dinheiro, o valor de troca.

Sob a régua inexorável do dinheiro, os homens assalariados aparecem integrados em termos de homogeneidade social e psicológica, enquanto comportamento profissional, mas não enquanto homens. Sua escala - palavra de ordem que se faz ouvir em todas as esferas da vida - é a utilidade; é ela que vem a tornar tudo mensurável, comparável e equiparável, enfim, homogêneo. Com efeito, essas palavras de Bataille (1993) fazem reverberar as postulações de Marx (2007), em que o capital significaria a perda do aspecto mais natural das relações sociais - entre os sujeitos e destes com a objetividade material -, visto que estas são substituídas por relações monetárias; trata-se de uma transformação das relações sociais em relações reificadas. Em suma, o trabalho - fragmentado, simplificado e abstrato - substitui o que outrora Marx conceituaria como autoatividade e se curva perante a lei do capital e da mercadoria. Embora alienado, devido à perda da consciência da totalidade de seu processo, o trabalho transforma-se no único vínculo que os indivíduos podem realizar com suas forças produtivas e com sua própria existência. Além disso, como já comentado, vida e trabalho distanciam-se cada vez mais, o que também significa que a reprodução da vida deixa de ocorrer como autoatividade nos termos de Marx (2007), ou seja, como produção natural da vida material e tudo que com ela se relaciona. Sendo assim, a vida material passa a se colocar como finalidade última e o trabalho como meio de seu alcance, meramente para assegurar sua existência.

Note-se que Marx desenvolve uma discussão fundamental, apresentada apenas superficialmente aqui, entre trabalho alienado e trabalho livre (autoatividade), cujo ponto fulcral de diferenciação se situa precisamente no conceito de utilidade. Para Marx, o objetivo do trabalho livre não se encerraria em produzir coisas úteis, já que "a produção de demasiado útil produz população demasiado inútil" (Marx, 2004 , p. 142). Desse trabalho participariam igualmente homem e natureza, de modo que o homem, ao transformar a natureza, estaria modificando a si mesmo, a sua própria natureza - e, nesse sentido, possibilitando seu próprio processo de individualização, ao significar o domínio do homem sobre o seu entorno, seu contexto e seus objetos, e não o contrário. Com isso, independência e liberdade fundar-se-iam através desse ato de autocriação; é através da ação, enquanto trabalho livre ou autoatividade, que o homem atua sobre a natureza, modificando-a, mas também transformando sua própria natureza interna e subjetiva, como um processo de autocriação (Fromm, 1979). Assim, a autoatividade diferencia-se do trabalho alienado e subjugado aos interesses 
da forma-mercadoria, visto que este aponta para uma impossibilidade de uma verdadeira emancipação do indivíduo e da sociedade. Pois somente por não responder a objetivos ou a ordens externas a si mesma, como algo instrumental, a ação - a autoatividade e o trabalho mostrar-se-ia capaz de possibilitar a liberdade.

A noção da utilidade reaparece nas palavras de Cacciari, ao debater sobre a emergência do "dever" como mais um dos lemas da metrópole, não menos sintomático da perda dos referenciais na contemporaneidade:

Cogito ergo sum: o cogito deve ser. [...] O dever incorpora o típico objetivo do domínio do pensamento sobre o ser, na medida em que esse objetivo de racionalização total não se apresenta imediatamente, mas é construído precisamente através de um ergo carregado de intenção ética e responsável pela "civilização". O dever deve ser cumprido enquanto este ergo existir. (Cacciari, 1993, pp. 56-57; tradução nossa) ${ }^{6}$

Cacciari toma como ponto de partida a emblemática conclusão cartesiana, símbolo da primazia do pensamento sobre a existência, para afirmar que a instauração e a generalização de sua lógica teriam levado ao aprisionamento do movimento ao âmbito do ergo. Com base na teoria da linguagem de Saussure, Cacciari sugere, em primeiro lugar, que a racionalidade almejada a partir de tal afirmação categórica de Descartes não seria um objetivo colocado no horizonte do devir, mas estaria já contido na própria forma e estrutura da linguagem. 0 cogito ergo sum confirma uma racionalidade imanente à própria linguagem, e não apenas um desdobramento do dever. $A$ linguagem é, por si própria, racional e não apenas o que dela se desdobra enquanto objetivo.
O que indica, novamente, que a transparência absoluta dessa racionalidade apenas vem a colocar o objetivo do dever em suspensão, ou seja, de maneira não explícita, porém não mais transcendental, mas imanente à sua própria engrenagem. A questão que emerge daí consiste em: como pensar outra realidade diferente da nossa, se até mesmo em termos de linguagem já estamos não apenas contaminados, mas quase que inteiramente moldados pela lógica e pela racionalidade vigentes?

Como uma espécie de consolo ou compensação perante uma condição de existência um tanto dramática, o ergo assume a imagem de uma fantasia, de modo a viabilizar a sensação de uma satisfação ilusória daquilo que não se pode obter. A fantasia, em termos de representação imagética do pensamento, abre mão do status da imaginação especulativa kantiana, para se tornar, ela mesma, a expressão da experiência do choque descrita acima:

A fantasia é também a dissolução desse tipo de imaginação teórica, que desempenha um papel fundamental em Kant. Agora já não é o pensamento que imagina. Antes, é o choque que se torna imagem e, portanto, a linguagem: o choque não está mais em busca de síntese, como no esquema anterior, e que, incapaz de encontrá-lo, se dispersa na fantasia e na ironia mas também o choque que amadurece a ponto de se construir como estrutura, onde torna manifestas as leis de seu próprio signo, onde ele se imagina a si mesmo. A imaginação não é um dever errante ou infindável, mas muito pelo contrário: é a análise, a postulação e a construção do modelo abstrato-formal do choque. A história tende inevitavelmente ao cálculo; a narrativa à combinação de signos; e a contradição e a divisão em direção ao desdobramento de uma equação. (Cacciari, 1993, p. 59; tradução nossa) ${ }^{7}$ 
Interessante destacar, nesse aspecto, que a fantasia assumia um papel de substantiva importância em pensadores como Freud (1990), para o qual as formas de autoridade dependem, para subsistir, de esquemas compensatórios que articulam a submissão aos desejos, o domínio aos afetos, o recalque e a neurose às promessas de realização individual. Seja nos termos da produção quanto nos termos da ciência - que busca por leis universais e, por isso, homogeneizantes - o heterogêneo, o diferente, o inconsciente, o transcendente e o não explicável - e, por isso, temível - encontram-se restritos ao universo da censura. Novamente Bataille, ao recuperar "Totem e Tabu" de Freud (ibid.), nos esclarece a ideia:

Na realidade heterogênea, os símbolos carregados de valor afetivo têm, assim, a mesma importância que os elementos fundamentais; a parte pode ter o mesmo valor que o todo [...]. Em suma, a existência heterogênea pode se representar em relação à vida ordinária (cotidiana) como inteiramente outra, como incomensurável, carregando essas palavras com o valor positivo que elas têm na experiência afetiva vivida. (Bataille, 1993, p. 18; tradução nossa) ${ }^{8}$

Nessa sociedade dos indivíduos úteis, o Estado emerge com o papel determinante de associação das mônadas fragmentadas e para a garantia dessa homogeneidade. E é nesse contexto da medida e da carência de afetos que Bataille (1993) localiza a emergência dos líderes fascistas. Sua conclusão desconcertante ancora-se em seus exemplos práticos do que seria o heterogêneo, visto que ele situa a emergência de líderes fascistas, tais como Hitler e Mussolini, justamente como expressões dessa heterogeneidade. Num universo enfadonho do igual e do equivalente, da dissolução do indivíduo nas massas, ações heterogêneas como as dos líderes do fascismo ganham destaque como verdadeiras expressões transcendentais com potencial quase hipnótico perante um público que busca por algum tipo de identificação, tal como nos explica Laclau (2013). É como se todo o fluxo de afetos, que não encontram amparo na realidade da medida, sentisse a necessidade desesperada de ser canalizado e, por isso, acabasse se atracando a esses expoentes heterogêneos singulares. Com efeito,

A incapacidade da sociedade homogênea de encontrar em si mesma uma razão de ser e de atuar faz com que dependa de forças imperativas, assim como a hostilidade sádica dos soberanos contra a população miserável os aproxima de qualquer formação que aspire a mantê-la em opressão. (Bataille, 1993, p. 24; tradução nossa) $)^{9}$

Em termos políticos, a exacerbação do heterogêneo emerge como instrumento diante de uma necessidade prática que se torna imperativa: o direcionamento ou a drenagem dos afetos recalcados por meio da criação de dualidades: heterogêneo e homogêneo, sagrado e profano, superior e inferior, puro e impuro. Nada mais sintomático do universo arquetípico do próprio mito.

A explicação da natureza heterogênea do líder - tal como um senhor ou um amo não reside em uma justificativa racional, mas se autorreferencia, como decorrente de algo que lhe é imanente, ou seja, contido em sua própria definição, que consiste em dominar seu servo. Irônico, senão deveras trágico, visto que, numa espécie de ato desesperado pela busca de encantamento nesse mundo desencantado, o homem tivesse optado pela pelas camélias vermelhas cheirando a tinta. 


\section{Entre a dialética negativa e a utopia urbana: 0 desvio}

Diante desse cenário apresentado, poderíamos assumir, como derradeira conclusão, que a forma urbana atual e a metrópole implicam decisivamente a homogeneidade, a dominação, a perda da individualidade? A discussão que empreendemos até aqui parece nos levar a um arremate inevitável: a metrópole e as massas como intrinsecamente conectadas e interdependentes, decorrentes dos devaneios da própria razão. Em que pese à tentativa de superação desse paradoxo por meio da análise corrosiva empreendida pelos pensadores da escola de Frankfurt, ao defenderem que a autocrítica da razão poderia ser capaz de eliminar esse seu componente regressivo, autores como Bueno (2015) indicam que isso ainda mostraria uma confiança no próprio potencial reflexivo da razão, o que não deixaria de levar a outra contradição. Retomemos o prefácio à Dialética do Esclarecimento:

A aporia com que defrontamos em nosso trabalho revela-se assim como o primeiro objeto a investigar: a autodestruição do esclarecimento. Não alimentamos dúvida nenhuma - e nisso reside nossa petitio principii - de que a liberdade na sociedade é inseparável do pensamento esclarecedor. Contudo, acreditamos ter reconhecido com a mesma clareza que o próprio conceito desse pensamento, tanto quanto as formas históricas concretas, as instituições da sociedade com as quais está entrelaçado, contém o germe para a regressão que hoje tem lugar por toda parte. Se o esclarecimento não acolhe dentro de si a reflexão sobre esse elemento regressivo, ele está selando seu próprio destino. Abandonando a seus inimigos a reflexão sobre o elemento destrutivo do progresso, o pensamento cegamente pragmatizado perde seu carácter superador e, por isso, também sua relação com a verdade. (Adorno e Horkheimer, 1985, p. 13)

Nas palavras de Bueno (2015, p. 152), "o que é comum a todas essas referências ao estatuto substantivo da razão para pensar suas próprias contradições é a persistência dos pensadores da teoria crítica na suficiência do pensamento dialético para empreender a tarefa de autorreflexão exigida na modernidade". Ou seja, mesmo na perspectiva de Adorno, em que se questionam a primazia da ideia e a relação de identidade entre forma e conteúdo, entre razão e realidade, ainda poderíamos alegar traços de uma abordagem sistemática. É nesse ponto que acreditamos ser imperativa a recuperação da análise dialética do filósofo Henri Lefebvre que, embora também reverbere influências da dialética negativa adorniana, acaba por complementá-la, ao dar um passo além e apontar para outro caminho, especialmente ao absorver influências de Nietzsche. Se a dialética negativa nos ampara ao questionar a identidade entre sujeito e objeto, mental e material, teoria e prática, frutos de um pensamento dualista ou mesmo de uma dialética positiva, essa perspectiva aparece retomada em Lefebvre com um outro viés, ao ressaltar os limites do próprio pensamento. Seu ponto de partida é o questionamento da possibilidade de dominação da realidade completa pelo homem e pela razão - em termos práticos ou pelo pensamento.

Como vimos em Cacciari, no que concerne à cidade, o pensamento dialético negativo denunciava a metrópole como uma espécie de totalidade coerente em que até mesmo as contradições se apresentam como parte de seu 
funcionamento; ou seja, questionava-se a existência das dualidades - presentes até mesmo na dialética materialista revolucionária - solúveis por meio de um movimento de síntese. Assim como no pensamento adorniano, tencionava-se explicitar os limites do pensamento humano, no sentido de contestar os pares conflitantes de outrora, visto que, ao menos na metrópole, as próprias oposições se mostram parte imanente de uma só lógica. Apesar de tal constatação também se mostrar presente em Lefebvre, o filósofo sinaliza para outro desdobramento em termos de um horizonte prático. Afinal, se a base mental tem seus limites, estes residem justamente no fato de que não são capazes de se realizar em sua totalidade - como numa identidade entre forma e conteúdo-, de maneira desprovida de contradições, seja para bem ou para mal. Lefebvre, portanto, tomará como enfoque a "passagem" do Logos propriamente dito - mental - para a concretude real e prática - material - e buscará as contradições inerentes a esse movimento.

Como aparece implicitamente desenvolvido por Lefebvre, em "El materialismo dialectico" (1999), e é enfatizado por Schmid (2012), o entendimento da constelação dialética lefebvriana envolve considerar alguns elementos fundamentais: 1) compreender que a realidade social é repleta de contradições e que disso decorre a necessidade de se colocar conceitos aparentemente completos e independentes (os sistemas, as dualidades) em diálogo, de modo a relativizar e buscar compreender que nenhuma abordagem pode ser plenamente verdadeira e absoluta em seu isolamento; 2) considerar, a todo momento, seu movimento de "suprassunção" - não apenas hegeliano, mas especialmente nietzschiano-, que, em suma, implica uma relação que se vale da negação e da absorção concomitantes, de modo a elevar o elemento negado/absorvido a outro nível e dando margem ao devir. Obviamente, nosso intento, ao enumerar tais condicionantes, é apenas auxiliar uma leitura mais fluida do autor, dada a complexidade de suas reflexões, mas jamais sistematizar seu pensamento ou sua abordagem, ou mesmo simplificá-lo e reduzi-lo a esquemas. Assim:

Para as discussões vivas, há alguma verdade em todas as ideias. Nada é inteiro e "inquestionavelmente" verdadeiro, nada é absolutamente absurdo e falso. Confrontando a tese, o pensamento busca espontaneamente uma unidade superior. Cada tese é falsa pelo que afirma absolutamente, mas verdadeira pelo que afirma relativamente (seu conteúdo); e é verdade pelo que ele nega relativamente (por suas críticas bem fundamentadas ao outro) e falsa pelo que ele nega absolutamente (seu dogmatismo). [...] Assim, a dialética, a relação imediata do pensamento com conteúdos diversos e mutáveis, não permanece fora da lógica. Ele se integra a ela, que ele transforma transformando. Torna-se vida, o movimento interno de pensamento, conteúdo e forma ao mesmo tempo. (Lefebvre, 1999, p. 13; tradução nossa) $^{10}$

Há uma crítica evidente à lógica formal em sua busca por sistematizar e categorizar a realidade, a partir de premissas e bases aristotélicas, em que temos as formas destituídas de seus conteúdos e afirmações que se pautam em relações identitárias. Entretanto, toda essa solidez e coerência almejada pelo pensamento - o mental - não se verificam na prática - entenda-se, no mundo prático-sensível, nas práticas sociais -, uma vez que todas as suas contradições, que pareciam inexistir, imiscuem-se e engrenam-se num jogo líquido 
e complexo do real. Tal é a dialética explicada por Lefebvre, em que opostos estão relacionados, integrados numa espécie de metamorfose e autodestruição concomitantes.

Note-se que não se trata apenas de negar a existência da lógica, de maneira sumária; como reitera Lefebvre, tudo pode ser verdadeiro e falso, em função das relações que estabelecemos e do contexto que situamos. Daí sua resposta para as questões que retoricamente coloca resumir-se, não raro, a sim e não. No entanto, o problema consiste em afirmar a possibilidade da existência de uma transparência - ou identidade - entre essa lógica mental e a prática individual/social, isto é, em tentar nos fazer crer que, de fato, esse mundo coerente, lógico, sistematizado, não apenas existe, mas pode vir a existir plenamente, criando uma fórmula identitária entre a realidade e sua imagem, mascarando e omitindo que tais elucubrações são fruto de nosso pensamento, um constructo social, uma teoria e, por fim, uma ideologia. E isso mostra-se válido para quaisquer tentativas de sistematização da realidade, seja quando falamos da utopia abstrata moderna pautada no progresso - o mito -, seja quando creditamos à razão a responsabilidade de se autoavaliar e conter, de maneira ascética, o temível espaço homogêneo do capital.

Em Lefebvre, a dialética não substitui ou elimina a lógica (o mental); com efeito, haveria uma junção (na contradição) entre a lógica e a dialética e, nesse encontro, surgiria o diferencial. A lógica relaciona-se com uma estratégia e com uma ciência do espaço; a dialética, por sua vez, tem a ver com a prática social e o conhecimento do espaço. Nas relações lógicas de identidades, não há devir; isto ocorre quando se atribui conteúdo, de modo que ele mesmo se torna uma diferença. É justamente esse tipo de abordagem lefebvriana - unindo, em suma, o movimento dialético entre o mental e o prático, no qual se insere o conceito de produção - que também abarca, inevitavelmente, uma atividade criativa (não planejada), o devir e o diferencial. Daí a insistência de autores como Schmid (2012) em afirmar que há, em Lefebvre, uma dialética tridimensional, ${ }^{11}$ relacionando Hegel, Marx e Nietzsche, algo que também aparece sugerido pelo próprio filósofo em diversos escritos. ${ }^{12}$

Por isso, lógica estaria integrada à ordem distante (longínqua), qual seja, do Estado e das relações de produção (e sua tendência à homogeneidade e à isotopia); a dialética, à ordem próxima, do local, da vizinhança, das topias (heterotopias). De sorte que o espaço social envolve uma multiplicidade de espaços e topias (heterotopias), subsistemas, ao qual o Estado capitalista busca conferir uma coesão e coerência, uma subordinação, através de uma ideologia que busque eliminar as possíveis contradições, seja na aparência ou na essência. Isso porque, na prática social (espaços de representação), não existe lógica; esta é impressa pelo mental (representações do espaço) através do Estado, através de uma estratégia. Não obstante, a "passagem" dessa lógica (mental, abstrata) para a prática (social, real) já implicaria uma dialética (relação com a totalidade do real e suas contradições), uma vez que esse movimento não é capaz de ocorrer sem contrassensos e incongruências.

Outra decorrência fundamental desse percurso pluridimensional lefebvriano seria a desvinculação da dialética dos sentidos tradicionais de temporalidade e da historicidade, o que nos sugere que ela não se baseia numa sequência lógica e coerente passado-presente-futuro, num encadeamento de fatos 
sucessivos e contingentes, tal como um desdobramento linear. Pois a história não se desdobra passivamente, mas se define a si própria, uma vez que é dotada de um sentido, um fim ou uma finalidade - não por isso fixa - que a orienta como uma realidade aberta. Contrapõe-se, especialmente, à história concebida como uma ciência parcelar (descritiva) que se autoproclama uma totalidade, incumbida de carregar a verdade, "como ciência total (do real e do ideal ou racional), como conhecimento simultaneamente da natureza, da sociedade, do pensamento" (Lefebvre, 1971, p. 144). Mais uma vez, o autor dialetiza a história, propondo uma "saída da história" como uma superação do "fim ${ }^{13}$ da história" por meio da suprassunção - levando-nos à pós-história -, ou seja, uma elevação do mesmo - a história e a historicidade - a outro nível, articulando-a ao espaço. Dessa maneira, Lefebvre anuncia a possibilidade de uma "história diferencial" e de uma utopia criadora ou concreta - o possível-impossível daquilo que (ainda) não existe.

Ora, no que se refere à noção de esclarecimento com a qual iniciamos este texto, Lefebvre rompe com a própria ideia de individualidade calcada numa dualidade inicial. Pois a dialética lefebvriana coloca em questão o próprio conceito de natureza, inclusive o presente nos Manuscritos econômico-filosóficos de Marx (2004). Neste, haveria uma relação de apropriação intrínseca entre o homem e a natureza, em consequência de seu "ser genérico", de modo que a não apropriação do homem sobre a natureza, em função do capital e através da propriedade privada, já envolveria uma primeira alienação. Já, em Lefebvre, a própria natureza - em sua idealização como uma realidade ou paisagem originária independente do homem - aparece negada em função de uma natureza segunda criada pelo homem: o urbano e a cidade (antinatureza ou não natureza). É nesse sentido que o urbano seria a superação de diversas oposições ou dualidades - por exemplo, entre cidade e natureza -, uma vez que ele próprio já seria uma natureza segunda, o que não significa a suplantação das contradições e dos desencontros (entre o real e o possível) que lhe são intrínsecos, como ressalta Martins (1996): "hoje está posto o problema da natureza segunda, criada pelo próprio homem, voltada contra ele - uma natureza que não se humaniza nem liberta o homem de limitações e reduções" (p. 15), visto que "a pobreza é pobreza de realização das necessidades criadas pelo próprio homem para sua libertação das carências que o colocam aquém do possível" (p. 19). Essa própria natureza segunda - a suprassunção dialética do homem e da natureza - seria, ela mesma, uma mediação: a mediação das mediações, esta a base para se compreender a individualidade moderna. Trata-se do espaço produzido, o urbano generalizado que se coloca como hipótese (possível) em Lefebvre.

Com efeito, na "problemática urbana" lefebvriana, a epistemologia urbana não poderia se ancorar na dualidade cidade versus campo, tampouco na dualidade cidade versus habitat, ou mesmo na antiga proposição sujeito versus objeto; no lugar, deve-se tencionar compreender os significados inerentes ao sentido do urbano, mais especificamente ao significado da forma urbana. Como bem observado por Brenner (2013), personagem de bastante relevância na atualização do pensamento lefebvriano, trata-se de construir um sentido para o urbano, de modo a se superar a limitada e insuficiente contraposição ao que seria o seu oposto, o seu externo (um outside). Possivelmente, estes 
seriam os novos limites a serem superados não apenas pelo esclarecimento (mental), mas por uma prática urbana (material).

Novamente, Lefebvre engendra um movimento entre forma - abstrata - e conteúdo prático-sensível -, de sorte que, ao afirmar que o urbano consiste em uma possibilidade, algo ainda não acabado e definido a mostrar uma direção e apontar para uma totalidade, intui-se dialetizar ambas as esferas mental e material. É por isso que o urbano, através do método já anteriormente realizado por Marx (2011) de redução dialética, ${ }^{14}$ poderia ser definido como forma pura, uma abstração concreta, a qual implica uma tendência ao encontro, à aproximação, à simultaneidade, muito embora sem conteúdo específico; consequentemente, à impossibilidade de se definir a forma urbana como sistema (o qual pressuporia algo fechado, sem travar relações externas), tampouco como objeto ou sujeito, pois há nela certa autonomia dentro da mutualidade entre formas e conteúdos. Seus conteúdos não são únicos nem homogêneos; são diversos, em formação e movimento. Daí o perigo de se priorizar - através de uma ideologia - apenas um dos conteúdos da cidade - seja o industrial, seja da circulação, da decisão -, de modo a favorecer apenas uma de suas funções, visto que tal procedimento não apenas simplificaria e empobreceria a cidade, mas principalmente se comportaria como instrumento de uma estratégia urbana. Nesse sentido, a forma urbana seria uma abstração concreta, uma vez que:

[...] tudo a ela vem e nela vive. Trata-se de uma abstração, mas, ao contrário de uma entidade metafísica, trata-se de uma abstração concreta, vinculada à prática [...]. Pode-se dizer que o urbano é forma e receptáculo, vazio e plenitude, superobjeto e não objeto, supraconsciência e totalidade das consciências. Ela se liga, de um lado, à lógica da forma, e, de outro, à dialética dos conteúdos (às diferenças e contradições do conteúdo). (Lefebvre, 2008, p. 110)

Essa cidade não apenas consome (como na indústria), mas também produz, mediante a aproximação de seus elementos:

A cidade atrai para si tudo o que nasce, da natureza e do trabalho, noutros lugares: frutos e objetos, produtos e produtores, obras e criações, atividades e situações. O que ela cria? Nada. Ela centraliza as criações. $\mathrm{E}$, no entanto, ela cria tudo. Nada existe sem troca, sem aproximação, sem proximidade, isto é, sem relações. Ela cria uma situação, a situação urbana, onde as coisas diferentes advêm umas das outras e não existem separadamente, mas segundo as diferenças. (Ibid., p. 109)

É nesse sentido que a forma urbana reúne em ato, numa totalidade ou síntese virtual, que gera um objeto virtual (o urbano). Destarte, a cidade não seria apenas um produto qualquer, mas uma obra privilegiada de cada modo de produção específico. A forma urbana relaciona-se com seu conteúdo sempre de maneira dialética, em que tudo pode ocorrer. Por fim, o espaço diferencial emerge como uma possibilidade de contraposição ao espaço do capitalismo; tal seria, para Lefebvre, como um élan vital, expressão que toma emprestado de Henri Bergson para indicar uma espécie de impulso ou energia original que geraria a vida. É assim que a cidade conforma um espaço de relações dialéticas, que abarca dentro de si o possível-impossível. Seus contraditórios não se excluem: o espaço urbano é o lugar da 
centralidade, as concentrações (implosão), encontros e reuniões, mas também das policentralidades, da dispersão (explosão), do isolamento, da segregação e da desigualdade.

Não obstante a investida da técnica em direção à homogeneização do espaço (isotopias), nenhum espaço pode excluir o outro completamente, ou segregar-se, isolar-se totalmente, ou mesmo ser completamente idêntico ao outro. Tal realidade, complexa, paradoxal, permeada por campos cegos, acaba preenchida e velada por uma representação ideológica (que preenche as lacunas), a saber, o urbanismo. Isto porque há uma confusão e sobreposição entre o industrial e o urbano, fazendo com que este apareça como mero efeito ou consequência do primeiro. Por isso, uma questão deve nos direcionar:

Pode-se afirmar que os fenômenos ligados à industrialização em determinado quadro global (institucional, ideológico) cederam lugar completamente aos fenômenos urbanos? Que a partir de agora estes subordinam aqueles? Certamente que não. Não confundamos tendência com o realizado. A sociedade atual situa-se na transição, e é nela que se pode compreendê-la. (Lefebvre, 2008, p. 125)

Em última análise, a utopia concreta lefebvriana viria a colocar igualmente a fruição e o prazer (em suas diversas acepções, inclusive o gozo) nesse horizonte do possível, ${ }^{15}$ em contraposição ao trabalho, o que não deixa de ser uma provocação, tanto para o universo do capital quanto para o ascetismo de certo marxismo ortodoxo. Pois, como analisa Stanek
(2014), mesmo o funcionalismo absoluto, ou melhor, o espaço do capital e da indústria de massas, tal como fortemente criticada por Adorno e Horkheimer, não tornam prescindíveis ou impossíveis momentos de genuína apropriação e emancipação. Ao dialogar com o próprio Lefebvre: "enquanto a utopia abstrata abraça os atuais protocolos de urbanização e os estendem para o futuro, a utopia concreta 'começa com o prazer e busca conceber um novo espaço'" (Stanek, 2014, p. xxxvi; tradução nossa). ${ }^{16}$

Como se pode ver, com Lefebvre, o momento negativo da dialética - embora imperativo, ao possibilitar a dissolução das representações, a desinstitucionalização do instituído, o descentramento do que parece estável - não prescinde de seu momento positivo - a negação da negação, o movimento de retorno a si. Pois a totalidade nunca se resumirá ao pensamento e às suas empreitadas sistematizantes, nem tampouco a uma suposta prática fortuita que se imagine destituída desse componente mental. Com efeito, é justamente a passagem entre ambos que imprime movimento e alimenta o devir, o diferencial, o possível-impossível; daí o termo produção ser tão sugestivo na proposta lefebvriana, ao unir, de maneira mediata - não imediata -, o mental, o prático e o diferencial. Este é o horizonte que o diálogo e o confrontamento entre os diversos autores propostos aqui parece delinear. Por ora, restaria ainda compreender melhor as possibilidades e limitações desse sentido da utopia concreta baseada na fruição e no gozo, em contraposição ao dever e à utilidade. 


\section{[I] https://orcid.org/0000-0002-4297-6656}

Universidade de São Paulo, Faculdade de Arquitetura e Urbanismo. São Paulo, SP/Brasil.

morita.akemi@gmail.com

\section{Notas}

(1) En la civilización griega, la ciudad es fundamentalmente la unidad de personas del mismo género $y$, por tanto, puede comprenderse cómo polis, una idea que remite a un todo orgánico, es anterior a la idea de ciudadano. En cambio, desde los orígenes - tal como narra el propio mito fundacional romano - en Roma la ciudad es la concurrencia conjunta, el confluir de personas muy diferentes por religión, etnia, etc., que concuerdan sólo en virtud de la ley.

(2) Veja, por exemplo, o debate de teóricos como Leach (2005) sobre a mimese, ao recuperar discussões empreendidas pelo próprio Walter Benjamin e Theodor Adorno.

(3) Vale destacar que a dissertação de Baudrillard, Sistema dos objetos, seria realizada sob a supervisão de Henri Lefebvre, seu professor na época.

(4) Lembre-se que o nascimento do habitat caminhou de mãos dadas com a industrialização e seu afã pela padronização, repetição, homogeneização, velocidade construtiva, racionalização e, ainda, pelo "novo" colocado no horizonte como a única via que parece nos prender de maneira inexorável. O habitat reduz-se, assim, ao acesso à propriedade privada, ao cumprimento de uma das funções urbanas corbusianas, seja na forma de conjuntos habitacionais padronizados, seja na dos subúrbios, criando redutos "utópicos" em zonas periféricas.

(5) "La base de la homogeneidad social es la procucción. La sociedad homogénea es la sociedad productiva, es decir, la sociedad útil. Todo elemento inútil queda excluido no de la sociedad total, sino de su parte homogénea. En esta parte, cada elemento debe ser útil para otro sin que la actividad homogénea jamás pueda acceder a la forma de la actividad con valor en sí. Una actividad útil siempre tiene una medida común con otra actividad útil, pero no con una actividad para sí".

(6) Cogito ergo sum: the cogito must be. [...] Duty embodies the typical aim of thought's dominance over being, inasmuch as this aim of all-inclusive rationalization does not present itself immediately, but is constructed precisely through an ergo charged with ethical intent and responsible for "civilization". Duty must be upheld as long as this ergo exists.

(7) Fantasy is also the dissolution of this kind of theoretical imagination, which plays such a fundamental role in Kant. Now it is no longer thought that imagines. Rather, it is shock that becomes image, and hence, language: shock no longer in search of synthesis, as in the previous schema, and which, unable to find it, disperses itself in fantasy and irony - but also shock that matures to the point where it constructs itself as structure, where it makes manifest the laws of its own sign, where it imagines itself. Imagination is not a wandering or an endless duty, but quite the contrary: it is the analysis, the postulation, and the construction of the abstract-formal model of shock. The tale tends inevitably towards calculation; the narration toward the combination of signs; and contradiction and splitting toward the unfolding of an equation. 
(8) En la realidad heterogênea, los símbolos cargados de valor afectivo tienen, así, la misma importancia que los elementos fundamentales; la parte puede tener el mismo valor que el todo [...] En resumen, la existencia heterogénea puede representarse em relación com la vida corriente (cotidiana) como enteramente otro, como inconmensurable, cargando estas palabras com el valor positivo que tienen en la experiencia afectiva vivida.

(9) La incapacidad de la sociedad homogénea para encontrar en sí misma una razón de ser y de actuar, le hace depender de las fuerzas imperativas, del mismo modo que la hostilidad sádica de los soberanos contra la población miserable les acerca a cualquier formación que aspira a mantenerla en opresión.

(10) Para la discusión viviente, hay algo de verdadero en toda idea. Nada es entera e "indiscutiblemente" verdadero nada es absolutamente absurdo y falso. Confrontando la tesis, el pensamiento busca espontáneamente una unidad superior. Cada tesis es falsa por aquello que afirma de manera absoluta, pero verdadera por aquello que afirma relativamente (su contenido); y es verdadera por lo que niega relativamente (por su crítica bien fundada de lo otro) y falsa por lo que niega absolutamente (su dogmatismo). [...] Es así que la dialéctica, relación inmediata del pensamiento con el contenido diverso y cambiante, no permanece ya fuera de la lógica. Se integra con ella, a la que transforma transformándose. Se convierte en la vida, el movimiento interno del pensamiento, contenido y forma a la vez.

(11) Lefebvre (2004) mesmo insistiria que a dialética do próprio Marx não seria binária, mas triádica, relacionando, por exemplo, terra, capital e trabalho.

(12) Por exemplo, Hegel, Marx, Nietzsche: the realm of shadows (2020), O fim da história (1971), como também em The production of Space (1991).

(13) Tomado em suas diversas acepções, podendo sugerir finalidade, término, acabamento (fechamento), mas também o fim da história revolucionário marxiano.

(14) Sua "forma mercadoria", no primeiro volume de O Capital.

(15) Tal posição é especialmente clara em Toward an architecture of enjoyment (2014), traduzido do manuscrito original em francês Vers une architecture de la jouissance. Em suas diversas acepções, jouissance poderia ser traduzido como prazer, gozo, divertimento, êxtase, fruição.

(16) While abstract utopia embraces current urbanization protocols and extends them into the future, concrete utopia "begins with jouissance and seeks to conceive of a new space, which can only be based on an architectural project". 


\section{Referências}

ADORNO, T.; HORKHEIMER, M. (1985). Dialética do esclarecimento. Rio de Janeiro, Zahar.

BATAILLE, G. (1993). El Estado y el problema del fascismo. Valencia, Pre-textos/Universidade de Murcia.

BAUDRILLARD, J. (1969). El sistema de los objectos. México, Siglo Ventuno.

BENÉVOLO, L. (2015). A história da cidade. São Paulo, Perspectiva.

BRENNER, N. (2013). “Introduction: Urban theory without an outside”. In: BRENNER, N. (ed.) Implosions/ Explosions: towards a study of planetary urbanization. Berlin, Jovis.

BUENO, S. F. (2015). Da teoria crítica ao pós-estruturalismo: breves apontamentos para uma possível confrontação entre Adorno e Deleuze. Educar em Revista. Curitiba, Editora UFPR, n. 56, pp. 149-161.

CACCIARI, M. (1993). Architecture and Nihilism: on the philosophy of modern architecture. Londres, Yale University Press.

(2010). La ciudad. São Paulo, Gustavo Gili.

DESCARTES, R. (1999). Meditações. Coleção Os pensadores, v. XV. São Paulo, Nova Cultural, pp. 233-334.

ELÍADE, M. (1972). Mito e realidade. São Paulo, Perspectiva.

FREUD, S. (1990). "Totem e Tabu”. In: FREUD, S. Edição standard brasileira das obras psicológicas completas de Sigmund Freud. Rio de Janeiro, Imago, v. 13, pp. 11-125.

FROMM, E. (1979). Conceito marxista do Homem. Rio de Janeiro, Zahar.

HORKHEIMER, M. (2002). Eclipse da razão. São Paulo, Centauro.

LACLAU, E. (2013). A razão populista. São Paulo, Três Estrelas.

LEACH, N. (2005). Mimesis. Architectural Theory Review, v. 10, n. 1, pp. 93-104. Disponível em: https:// www.tandfonline.com/doi/abs/10.1080/13264820509478531. Acesso em: 14 jan 2021.

LEFEBVRE, H. (1971). O fim da história. Lisboa, Publicações Dom Quixote. (1973). A reprodução das relações de produção. Porto, Publicações Escorpião. (1991a). A vida cotidiana no mundo moderno. São Paulo, Ática. (1991b).The production of space. Oxford, Blackwell Publishing. (1999). El materialismo dialéctico. Ediciones Elaleph.com. Disponível em: <https://www. infoamerica.org/documentos_pdf/el_materialismo_dialectico.pdf>Acesso em: 15 jan 2020.

(2004). Rhythmanalysis: space, time and everyday life. Londres, Continuum. (2008). A revolução urbana. Belo Horizonte, Editora UFMG. (2014). Toward an architecture of enjoyment. Minneapolis, Minnesota University. (2016). O direito à cidade. São Paulo, Centauro. (2020). Hegel, Marx, Nietzche: the realm of shadows. Londres, Verso. 
MARTINS, J. de S. (1996). "As temporalidades na História na dialética de Lefebvre". In: MARTINS, J.de S. (org.). Henri Lefebvre e o retorno à dialética. São Paulo, Hucitec.

MARX, K. (2004). Manuscritos econômico-filosóficos. São Paulo, Boitempo. (2007). A ideologia alemã. São Paulo, Boitempo.

(2011). O capital: crítica da economia política - Livro I: O processo de produção do capital. São Paulo, Boitempo.

SCHMID, C. (2012). A teoria da produção do espaço de Henri Lefebvre: em direção a uma dialética tridimensional. GEOUSP - espaço e tempo, São Paulo, n. 32, pp. 89-109.

SIMMEL, G. (2005). As grandes cidades e a vida do espírito (1903). Mana. Rio de Janeiro, v. 11, n. 2, pp. 577-591. Disponível em: <http://www.scielo.br/scielo.php?script=sci_arttext\&pid=S010493132005000200010\&lng=en\&nrm=iso >. Acesso em: 14 jan 2021.

STANEK, Ł. (2014). "Introdução: A manuscript found in Saragossa". In: LEFEBVRE, H. Toward an architecture of enjoyment. Minneapolis, Minnesota University.

Texto recebido em 4/out/2019

Texto aprovado em 2/nov/2020 